\section{Disorder of pericardial fluid cholesterol metabolism in cholesterol pericarditis}

To the editor: Since Alexander's first report in 1919 (1), cholesterol pericarditis has been used to denote cases of chronic pericardial scintillating gold paint-like effusion with cholesterol crystal. However its etiology remains unknown, although three hypotheses were introduced on the basis of the 47-cases review of Brawley et al (2). We have experienced this particular kind of case, and found an imbalance in the lipoprotein analysis of the pericardial fluid (PF), which is possibly responsible for cholesterol crystals.

In October 1989, a 33-year-old postman with dyspnea and anasarca was first referred to our hospital. ECG was low voltage but no alternans. Chest X-ray showed a massive cardiac shadow, and cardiac tamponade was diagnosed with echocardiogram, because of the findings of right ventricular diastolic collapse (3) and backward motion of the anterior right ventriculum which continued more than $50 \mathrm{msec}$ after mitral valve opening (4). Pericardiocentesis was performed immediately, and $650 \mathrm{ml}$ of fluid was aspirated with innumerable gold paint-like cholesterol crystals. Serum cholesterol was $71 \mathrm{mg} / \mathrm{dl}$, free $\mathrm{T}_{3} 2.3 \mathrm{ng} / \mathrm{dl}$, free $\mathrm{T}_{4} 1.09$ $\mathrm{pg} / \mathrm{dl}$, TSH $3.77 \mu \mathrm{U} / \mathrm{ml}$. Neither rheumatoid factors nor antinuclear antibodies was positive. Cultures of blood, PF, urine and gastric juice were subsequently negative for acidfast organisms, fungi, and any kind of virus and bacteria. Specific gravity of PF was 1.039 . PF appeared to be an ultrafiltrate of plasma, since electrolytes were present in PF in concentrations compatible with such an ultrafiltrate (5). The cholesterol concentration of the fluid was $77 \mathrm{mg} / \mathrm{dl}$, whereas normal PF cholesterol is 20 to $40 \mathrm{mg} / \mathrm{dl}$ (6). In almost all cholesterol pericarditis cases, $\mathrm{PF}$ cholesterol was reported to be over $70 \mathrm{mg} / \mathrm{dl}$ (2). Fluid level is not likely to reflect the exact cholesterol amount of the intrapericardium, for cholesterol crystals are not included in the fluid cholesterol level [PF cholesterol of some reported cases was not elevated (7)].

Lipoprotein analysis in serum and PF is shown in Table 1. Although little has been reported concerning both apoprotein and lipoprotein of normal PF, LDL-cholesterol (LDL-chol.) of Table 1 is higher in PF than in serum; on the contrary, apoB is extremely low in PF compared with serum. This discrepancy is easily recognized in the ratio of LDLchol./apoB at the bottom of Table. This observation supports the fact that cholesterol crystals attribute to the lower affinity for water due to the apoB breakdown.

In this particular case, one supportive evidence for the disorder of cholesterol metabolism in vivo was detected.
Table. Comparison of Pericardial Fluid with Serum through the Analysis of Total Cholesterol, Lipoprotein and Apoprotein

\begin{tabular}{llcc}
\hline & & Serum & Pericardial fluid \\
Total chol. & $(\mathrm{mg} / \mathrm{dl})$ & 71 & 99 \\
HDL-chol. & $(\mathrm{mg} / \mathrm{dl})$ & 25.7 & 7.3 \\
LDL-chol. & $(\mathrm{mg} / \mathrm{dl})$ & 38.3 & 87.1 \\
VLDL-chol. & $(\mathrm{mg} / \mathrm{dl})$ & 5 & 4.6 \\
apoAI* & $(\mathrm{mg} / \mathrm{dl})$ & 54 & 42 \\
apoAII* & $(\mathrm{mg} / \mathrm{dl})$ & 9 & 5 \\
apoB* & $(\mathrm{mg} / \mathrm{dl})$ & 31 & 8 \\
apoCII* & $(\mathrm{mg} / \mathrm{dl})$ & $<0.5$ & $<0.5$ \\
apoCIII* & $(\mathrm{mg} / \mathrm{dl})$ & $<1.0$ & $<1.0$ \\
apoE* & $(\mathrm{mg} / \mathrm{dl})$ & 2 & 2.4 \\
& & & 10.9 \\
LDL-chol. $/ a p o B$ & 1.24 & \\
\hline
\end{tabular}

* Turbidimetric Immunoassay (TIA).

Eisei NOIRI and Takashi ITOH

Division of Cardiovascular Diseases, Tokyo Teishin Hospital, Tokyo

\section{REFERENCES}

1) Alexander JS. A pericardial effusion of "gold paint" appearance due to the presence of cholesterin. Br Med J 4: 463, 1919.

2) Brawley RK, Vasko JS, Morrow AG. Cholesterol pericarditis. Am J Med 41: 235, 1966.

3) Singh S, Wann S, Klopfenstein HS, Hartz A, Brooks HL. Usefulness of right ventricular diastolic collapse in diagnosing cardiac tamponade and comparison to pulsus paradoxus. Am J Cardiol 57: 652, 1986.

4) Engel PJ, Hon H, Fowler NO, et al. Echocardiographic study of right ventricular wall motion in cardiac tamponade. Am J Cardiol 50: 1018, 1982.

5) Lorell BH, Braunwald E. Heart disease. in: Pericardial disease, Braunwald E, Eds. 3rd ed. Vol. 2; Saunders, Philadelphia, 1988, p.1484.

6) Gaspar IA. Cholesterol pericarditis: The third autopsied case in the United States with a study of its histogenesis. J Med Soc N J 79: 323, 1982.

7) Szatkowski J, Inoue T. Cholesterol pericarditis - an unusual case of probable tubercular origin in a patient with rheumatoid arthritis. Am J Cardiol 12: 730, 1963. 